sob um enfoque sacio-interacionista, ainda que o termo se identifique mais propriamente com as posturas piagetianas, conforme ensina Cláudia Lemos (1986) (9) Nessa linha de uma quase confluência entre os dois autores, encontram-se também algumas observaçōes de Emili Ferreiro (1986) e de Hermine Sinclair (1987), estudiosas que trabalham em linha teórica mais rigorosamente piagetiana. Diz a primeira, no último parágrafo de sua obra "Psicogenese da Lingua Escrita", quando se reporta à importância de se contruir uma pré-história da escrita:

"Ao finalizar nosso trabalho, descobrimos que estávamos fazendo, sem o saber, o que Vygotski tinha claramente assinalado há décadas." (10)

Hermine Sinclair, por seu turno, em pronunciamento feito durante uma discussão, na qual se pretendiam confrontar os pontos de vista teóricos de Piaget com os de Vygotski, pontua que:

"embora cada um dêe ênfase a uma parte do desenvolvimento, provavelmente os dois estäo mais próximos um do outro, do que se pensa..." (11)

Acreditamos também nós que as semelhanças entre Piaget e Vigotsky devam ser mais numerosas que as diferenças. No entanto, percebemos nitidamente que tais divergências existem, mostram-se relevantes e precisam ser analisadas, pois não só tangenciam, mas antes atingem pontos vitais de estudos do desenvolvimento, da aprendizagem, da linguagem, seja do ponto de vista psicológico propriamente dito, seja do ponto de vista epistemológico.

Desta forma, muitas outras questöes como: formaçăo dos conceitos na criança; etapas para geração de conceitos: conceitos espontâneos e científicos; função e papel da escola; zona de desenvolvimento proximal, mostram-se de fundamental importância para estudos e discussöes, principalmente para aqueles que procuram dar conta não só de algumas indagaçöes básicas referentes ao problema das relaçöes, pensamento e linguagem, mas ainda de alguns impasses teóricos relacionados ao ensino de língua materna, sobretudo quando se visa à prática pedagógica.

Deixamos, pois, aqui registrados para o leitor alguns outros pontos que mereceriam discussóes amplas e que, no momento, extrapolam os limites deste texto.

REFERENNCIAS BIBLIOGRÁFICAS

1. VYGOTSKI, L.S. Thought and Language. USA, MIT Press, 1962.

2. CHOMSKY, N. Intervençōes em Debate com Jean Piaget e outros. In: Piattelli Palmarini. Theories du Langage. Theories de l'Apprentissage. Paris, Seuil, 1979.

3. PIAGET, J. Intervençöes em Debate com N. Chomsky e outros. In: Piattelli Palmarini, op.cit

4. MONOD,J. Intervençöes em Debate com J. Piaget e N. Chomsky. In: Piattelli Palmarini, id. ib., p. 211.

5. CHOMSKY, N. id. ib., p. 255.

6. PIAGET, J. "Comentarios sobre las observaciones críticas de Vygotski". In: Pensamiento y Lengruaje (Prólogo). B. Aires, La Pleyade, 1984, p. 202

7. PIAGET, J. "Comentarios sobre las observaciones críticas de Vygotski". In: op. cit. p. 205.

8. PIAGET, J. id. ib., p. 206

9. LEMOS, C. T. "Interacionismo e Aquisiçäo de Linguagem". rev. Delta, 86. 10. FERREIRO, E. e TEBEROSKY, A. Psicogennese da Língua Escrita. Porto Alegre, Artes Médicas, 1986, p. 282.

11. SINCLAIR, H. "Discussão" in FERREIRO, E. e PALACIO, M. G. (orgs.). Os Processos de Leitura e Escrita. Porto Alegre, Artes Médicas, 1987, p. 273.

Artigos

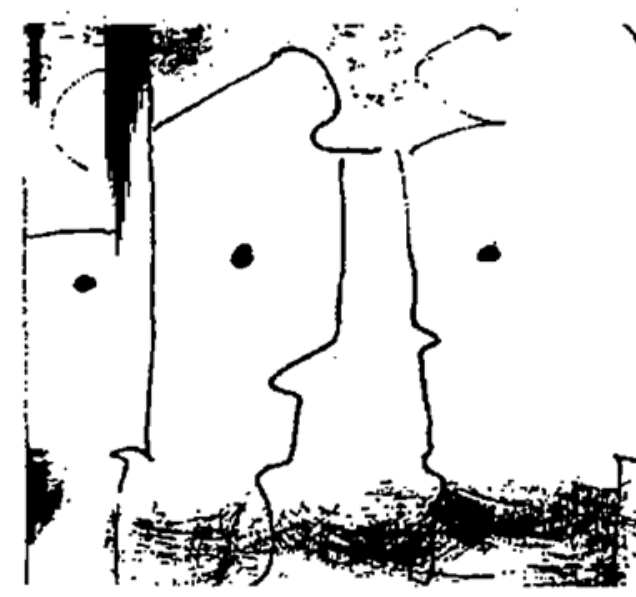

\title{
O CONTO E O ENSINO DA LITERATURA
}

Jean Verrier

T staé a única exposição deste colóquio sobre a questão do ensino. Por isso acho indispensável relatar, para situá-la melhor, de quais experiências estou partindo.

Sou responsável, na Universidade de Pari VIII - Vincennes, por um curso de poética da narrativa, que me levou a várias missōes em Haute-Volta e a dirigir pesquisas de estudantes africanos sobre serōes de leituras de contos; conduzo também um seminário de formaçăo contínua de professores de francês e pertenço à Associação Francesa de Professores de Francês (A.F.E.F.), cuja revista dirijo: $O$ Francês, hoje. Estou, portanto, numa espécie de encruzilhada e, assim, minha exposição abarcará vários domínios: a oralidade, o ensino, a semiótica. Não seguirei, no entanto, progressäo linear de um a outrodomínio. Trata-se sobretudo de um discurso "em constelação" - as questōes relacionadas mantêm suas diferenças e suas aberturas.

O Sucesso dos Contos

Há uma dezena de anos os contos vêm sendo objeto de grande interesse na

FProfessor de Literatura Francesa da Universidade de Paris VIII, Vincennes-Saint Denis

França, não apenas junto a pesquisadores, mas também junto a estudantes (a criação em 1976, da revista Cadernos de Literatura oral,por J. Dournes), junto ao grande público (a criação de novas coleçōes como "Narrativas e contos populares". pela Gallimard; "Rio e Chaman", sob direção do Conselho Internacional da Língua Francesa...), e através da difusáo de obras críticas em ediçöes de bolso (Morfologia do conto, de V.Propp; Psicanolise dos contos de fadas, de B.Bettleheim...), Henri Gougaud contou pelo rádio, numa hora de grande audiência, as grandes lendas da humanidade e pode-se perguntar se certas formas de narrativas pelo rádio e televisāo (as de J.Antoine e P.Belleware) nâo representariam uma forma moderna do conto de transmissáo oral

As revistas pedagógicas de ensino da língua francesa também dedicaram numerosos artigos aos contos: O Francés, hoje 43, setembro 1978; Breve 14, maio de 1978 e 11, setembro de 1977; Práticas 11-12, novembro de 1976 e, no estrangeiro, Québec francês 27, outubro de 1977. Recentemente, O Correio da UNESCO (janeiro de 1979) publicou um artigo do escritor equatoriano].E. Adoum: "As Fadas 
para o melhor e o pior". Afinal a revista do departamento de Literatura francesa da Universidade de Paris VIII (ediçōes Larousse), Literatura, prepara um número inteiramente consagrado aos contos (no. 45, fevereiro de 1982).

De modo mais permanente, mais institucional, aparecem manuais: $O$ Conto, a Poesia (coleção "Literatura e linguagens", ed. Nathan, 1974), para o segundo ciclo do ensino secundário; O fio de Ariane (Nathan, 1980), para a escola primária. Produz-se material pedagógico, como O Tarot dos Mil e um contos (ed. de L'Ecole, 1977) inspirado nolivro de Italo Calvino: Il Castelo dei destin incrociati. Anne Hénault, no seu livro Os Jogos da semiotica (Presses Univ. de France, 1979) anuncia a preparação de um manual de análises de textos a partir de conceito semí́ticos, com livro do aluno e livro do professor. Dessa forma, o interesse pelos contos se liga à difusão de análise semióticas.

\section{Quais contos?}

A função da oralidade nos contos fica bastante ambígua, se considerarmos modo como chegam ao grande público, estudantes ou alunos. Jack Goody, Pau Zumthor, Jacques Dournes, Vilmos Voigt, para citar apenas alguns, enfrentaram neste colóquio, cada um a seu modo, delicada questão da definição da oralidade. A pertinência de tal questão, no entanto ainda não está clara para muitos editores. A distinção entre contos recolhidos hoje, ao vivo, com gravador, e contos reunidos, frutos de compilação de publicaçōes antigas, muitas vezes com um século aparece de modo precário, por exemplo, no aparelho editorial da coleçăo "Narrativas Contos Populares" (Gallimard). A iconografia trabalha no mesmo sentido, embaralhando as diferenças entre foto amareladas de antigamente e clichês completamente novos.

No seu prefácio aos.Contos do velho-velho tempo, recolha de contos de Henri Pourrat Michel Chrestien,(1969) zomba das reservas feitas por Paul Delarue (autor do catálogo comentado do conto popular francês), quando da publicaçáo do Tesouro dos Contos de Pourrat. M. Chrestien escreve:

"Os "folcloristas" declararam seu fastio. Um certo Paul Delarue escreveu numa revista especializada: "Estes não săo contos populares..." Eviva oFolklore ci-en-tí-fi-co. Como se isso não existisse apenas em anfiteatros empoeirados."

E zomba também da citaçăo dos irmãos Grimm como modelos que se vangloriavam de sua fidelidade, veracidade, e de nada terem acrescentado de sua própria lavra, aos registros. Mais adiante dá a palavra a Pourrat:

"Basta registrar os contos - o que já não é fácil? Nove em dez vezes ele são recontados superficialmente... Que a transcriçăo se torne uma criaçāo."

Falemos dos irmãos Grimm. Numa notícia da reedição em coleção de bolso Folio, de 1973, prefaciada por Marthe Robert, J. Cl. Schneider afirma que é pelo desejo de "encontrar a forma primitiva" que os irmajos Grimm combinam as diferentes versöes que possuem, "apuram a relação lógica dos episódios..." "aperfeiçoando apesar dele (Wilhelm Grimm), as tradiçőes orais e lhes conferindo uma graca e singeleza que nem sempre possuíam."

A mesma ambigüidade na função da oralidade dos contos se encontra naqueles que os analisam. Louis Marin, aqui mesmo, na sua leitura tăo sugestiva de Pele de Asno, reconhecerá, estou certo, ter trabalhado com a escritura de Perrault e com a representaçáo da oralidade, mas não com as pectos da transmissäo oral do conto. As análises de Bettleheim também se referem às versóes escritas: as de Perrault, Grimm, Andersen. Greimas abre seu estudo sobre "um problema de semiótica narrativa: os objetos de valor" (Langages 31, setembro de 1973) afirmando que:

"Escolher como corpus de referência o universo dos contos maravilhosos constitui garantia quanto à universalidade das formas narrativas que se pode a reconhecer."

Entretanto, deixando de lado o estudo de 33 versöes lituánicas da "busca do medo" (A.T. 326) recolhido em Sobre o Sentido (1970), Greimas parte freqüentemente de versōes já remodeladas. Na Semantica estrutural (1966) ele parte do modelo proppiano, e não dos contos de Afanassiev. Do mesmo modo Claude Bremond, Logica da narrativa (1970), parte das análises de Dundes ou dos resumos que fornece no Morfologia dos Contos indígena norte-americanos, e não das traduçōes dos contos e indígenas por Boas.

Năo é o caso de procurar a todo custo um pureza do conto oral, bastante hipotética sobretudo nas nossas sociedades. Sabe-se que circulavam entre o povo versōes orai de Pele de asno", antes que Perrault fixasse uma versăo escrita que, por sua vez alimentou infinitas novas versōes orais entre os iletrados dos séculos seguintes, através dos divulgadores orais. É verdade que também as versōes orais dos "catálogos" como as do Conto popular francés de P.Delame e M.L.Teneze (1957, 1964 1976) săo fixadas, condensadas (mas săo conhecidas apenas por especialistas e não têm trânsito entre o povo).

Entretanto há ainda situaçōes em que o conto de transmissão oral pode circular. estudantes africanos nos fazem agora numerosos trabalhos de coleta, tradução, comentários (com o risco de que, tornando-se professores, a difusăo escrit de seus trabalhos modifique o jogo da transmissão oral, como assinalou J. Goody); alunos do liceu técnico de Limoges (de 15 a 18 anos), no centro da França realizaram, entre 1974-1975, um trabalho de coleta, tradução e identificaçāo de contos da sua região. O gravador, o cinema, o vídeo permitem e permitirão, cada vez mais, observar e estudar os contos de transmissão oral preservando aquilo que os contistas africanos chamam "o tempero", "os condimentos": gestos, entonação, reaçōes do público. Sầo casos privilegiados onde a pedagogia do texto está ligada a sua constituiçăo.

O que espanta não é, portanto, a ambigüidade da funçáo da oralidade nos contos, mas sim o fato de que ela nem sempre seja reconhecida e que seja disfarçada por uma espécie de contradiçāo, onde às vezes se valoriza a oralidade ligando-a ao "popular" (conto "popular" por conto de transmissäo oral, ou conto de "tradição" oral ao invés de conto de transmissāo oral) e mediando tudo pela escritura, o que se justificaria apelando ao respeito que se tem a essa literatura oral e popular. O que está, portanto, em jogo? Tentar anular a ambigüidade, considerar a oralidade enquanto tal, seria talvez colocar, tanto no campo da análise como no do nsino, um certo número de elementos geralmente recusados: o sujeito (enunciador e coletor): "O sujeito do discurso oral näo é o mesmo do discurso escrito" (J.Cl. Coquet, Sémiotique Littéraire); a ideologia, os grupos sociais, as estruturas sociais nas quais os contos circulam e das quais são elementos constituintes; a historia das transformaçöes, que era a finalidade primeira e principal de Propp: a pesquisa das raízes históricas e dos modos de transformação dos contos.

\section{O Oral no Ensino do Frances}

Gostaria de alargara questäo do ensino dos contos de transmissăo oral para a questăo do ensino do oral e lamento que não tenhamos tido tempo de discutir, neste colóquio, as conseqüências pedagógicas para a aprendizagem das línguas da comunicação de J.Cosnier que, através de uma rica tipologia dos meios de comunicação, mostrou de que modo o verbal está estreitamente ligado ao năo-verbal e, em particular, ao gestual.

No congresso de Associação francesa dos professores de francês, em 1977 (ver o resumo no Francés hoje.41, março de 1978), Pierre Bourdieu afirmava que o uso da linguagem na escola coloca questōes fundamentais para sociolingüística e para a instituição escolar. Por exemplo: "Quais 
são as condiçōes de possibilidade de uma comunicação oral?"

Desse ponto de vista, seria preciso refletir sobre a função das provas orais no diferentes exames e concursos. O ora ocupa lugar importante nos concursos de ingresso das escolas políticas: Ciências Políticas, Escola Nacional de Administração, lugar muito mais importante do que nos concursos das grandes escolas científicas como Politécrica.

Isto permite matizar bastante a proposição segundo a qual o oral estaria ligado ao "popular". Ensinar o oral, sim; mas qual oral? Creio que J. Cosnier fez mal em querer minimizar, nas manifestaçōes orais a presença de diferenças resultantes das diferentes classes sociais - mesmo que apareçam no interior de uma sociedade isofônica. Os trabalhos de W. Labov săo, nesse sentido, de capital importância.

As instruçōes ministeriais de 1972 sobre o ensino do francês recomenda a passagem progressiva do oral ao escrito, única instância "adornada" com virtudes intelectuais, afetivas, estéticas. Por outro lado falar bem seria falar como se escreve como se essas fossem duas "ordens" diferentes. Mas passar ao escrito é também passar àquilo que fica e pode ser controlado, anotado. M. de Certeau, J Revel e D. Julia, no seu livro Uma polftica do lingua - A Revoluça francesa $e$ as grira (Gallimard, 1975) mostraram como, na pesquisa do abade Gregório, o oral aparece como uma ameaça para os intelectuais (os "notáveis") exatamente por estar ligado a mudanças. Rousseau também desejava quese fixasse a pronúncia do mesmo modo como, através da ortografia, o escrito está fixado. Carla Casagrandee Silvana Vecchio lembraram, aqui mesmo, que na Idade Média "a comunicação oral é regulada por sistemas normativos bastante precisos".

Voltamos então às questōes de Bourdieu: pode-se mudar a língua no sistema escola (levando verdadeiramente em conta oralidade?) sem mudar todas as leis que definem o valor dos produtos lingüísticos das diferentes classes no mercado, ou sem mudar as relaçōes de dominação? E esta outra questāo dupla: "Uma língua oral que se ensina na Escola é ainda oral? Uma Escola que ensina o oral é ainda uma Escola?"

\section{Sete razoes para estudar os contos na classe}

Gostaria agora de me desviar um pouco das questōes que acabo de colocar sobre a função do oral e dizer qual é, para mim e para muitos professores a partir de sua prática, o interesse pedagógico dos contos. Escolhi, de maneira um pouca arbitrária mas talvez simbólica, já que se trata de contos, sete aspectos principais:

1. São histórias para crianças (nem sempre) cuja análise e a própria possibilidade de dupla leitura interessam e chegam a apaixonar estudantes e professores, como
Louis Marin acaba de nos dar um brilhante exemplo.

2. Oferecem material privilegiado de textos curtos, que se pode ler na versão integral, quando se elimina o critério dos "trechos escolhidos".

3. São textos cujo sentido (um sentido) pode ser apreendido desde o início, globalmente, ao contrário de uma tradiçâo que acredita ser preciso primeiro escrever e ler uma fráse, depois um parágrafo, para só então fazer uma narração - isto é, constituir um sentido global por adição, o que é mais do que contestável. Aprendero sentido globalmente permite aos estrangeiros, entre outros, fazer um primeiro trabalho de reconhecimento, de situação e de análise, a partir das versōes orais integrais que trocam entre si, na situação de um curso, por exemplo.

4. Os contos são textos que se apresentam em séries. Existem apenas "versōes". O texto definitivo está para ser constituído. Ele não é dado de saída, como é costume no ensino dos textos literários, e isso pode levar a modificar a idéia que se tem dos próprios textos literários e, naturalmente, do seu ensino. Encontramos aqui os trabalhos de J.Bellemin-Noel, na França, $e$ de G.F.Contini, na Itália, sobre os "pré-textos".
5. No momento em que se estudam mais $\propto$ textos do que autores, os contos permitem colocar a questão do autor como indivíduo entre parênteses, já que são frutos de um imaginário coletivo.

6. Quando se trata de uma coleta verdadeira, como no caso dos alunos de Limoges ou dos estudantes africanos, a tomada de consciência da diferença entre 0 escrito e o oral é imediata: problemas do contato, da situação, da transcrição, da tradução, etc...

7. Os contos têm formas simples que permitem, da escola primária à universidade, o reconhecimento de suas estruturas de significaçāo. Por exemplo, no curso primário (8 anos) é possível analisar a estrutura de um conto e reescrever um outro conto a partir do primeiro (a história de Coelho que procura uma casa $e$ encontra uma sucessâo de obstáculos transforma-se na do Porco que procura alimento). Na universidade, a partir de um corpus de versōes, contrói-se um modelo, depois se reescrevem novas versōes, suprimindo todos os elementos "maravilhosos" (ver O Francês Hoje 43). Nota-se a dificuldade das crianças em mudar os atores conservando os mesmos actantes. (Nota) O trabalho com contos na sala de aula nâo é, portanto, um simples acréscimo ao ensino da literatura. Embora sejam tipos de textos muito diferentes, as características próprias dos contos de transmissão oral chamam a atençăo para certos traços literários aos quais nấo se tinha dado destaque suficiente $e$, através do estudo dos contos, reencontramos algumas perspectivas contemporâneas do textos literários que, assim, são confirmadas.

(NT) O termo "actante" remete a um modelo de sintaxe narrativa de base semiótica: trata-se de uma unidade
sintática do enunciado narrativo, isto é, uma das funçöes desse enunciado, que corresponde, de certa maneira, ao personagem visto através da sua esfera de açâo.
A Análise Semiótica dos Contos

\section{Exame de um manual}

Os trabalhos sobre contos propostos nos manuais das aulas de francês fazem quase sempre referências teóricas, de modo mais direto ou menos direto, às análises semióticas. Gostaria de examinar rapidamente um desses manuais, o mais recente, lançado pelas ediç̧̄es Nathan em junho de 1980.

O fio de Ariane ou o prazer dos contos, destinado a alunos do curso médio ( 8 a 11 anos)é uma antologia de contos de Grimm, Perrault, Andersen, La Fontaine, narrativas bíblicas (traduzidas por L. Segond, 1910), mitos e lendas da Grécia antiga, contos das mil e uma noites e 2 ou 3 contos de escritores contemporâneos. Essa antologia é acompanhada de uma orientação metodológica e de uma "ficha do professor", o que the permite desenvolver umas trinta aulas ao longo do ano escolar.

Os autores, três professores de Ècole Normale d'Instituteurs, afirmam que sua finalidade é iniciar os alunos nos códigos culturais-míticos, simbólicos, religiosos que marcam toda a nossa cultura ocidental mas, que são ignorados; é ainda tornar os alunos sensíveis à năo - inocência dos discursos; é também fazê-los compreender um texto como sistema de signos organizados. Eles vêem nos contos de sua antologia (todos "literários"), 2 "estruturas de base": uma estrutura do tipo Falta + Saber ("A Bela Adormecida no Bosque", "Barba Azul", a história de Adão e Evia) e uma estrutura do tipo Busca (sem Falta), comoem "Cinderela". A Busca se subdivide em 3 tipos: heróica, quando o herói tem virtudes guerreiras; cristă, quando tem virturdes cristâs; popular, quando as duas primeiras cenas sáo retomadas com valores invertidos ("O gato de Botas", "O Pequeno Polegar")

Essas análises são simples, na medida certa do público ao qual se destinam. Desagradável é que sejam apresentados como dados do texto e não como 
contruçöes dos analistas, o que conduz a afirmaçöes contestáveis, onde o conto nunca tem a última palavra. Por exemplo; os autores afirmam que a combinação Falt + Busca existiria apenas nas produçōe recentes e que seria "pouco comprovada nos contos tradicionais", o que nāo deixará de surpreender aos folcloristas. Acontece que o conto acaba criticado em nome do modelo: "Desprezando toda lógica, narrativa se transforma em narrativa da busca heróica" (p.52 de Fichier). Por tod parte se encontra a idéia do sentido único e escondido: "A estrutura nos ensina sobr a significação profunda" (p.16). Quanto à "análise dos temas simbólicos e míticos" (p.28), parece mais uma chave dos sonhos, um quadro de concordâncias.

Esta tipologia sumária e rígida está ligada a um caminho pedagógico muito normativo, mesmo prevendo um tempo, no final do ano, para "uma criaçăo livre". Dois exemplos entre outros (pp. 27 e 26 de Fichier):

I - Objetivos da seção. 1. Deixar que as crianças encontrem uma estrutura: a da busca popular.

Expressão livre: O professor deverá organizar as intervençōes espontâneas do alunos, inscrevendo-os, tendo em vista síntese final; isto é, sabendo de antemaa que deverá chegar ao quadro acina.

Compreendo bem a intenção dos autores, e confesso não conhecer tăo bem quant eles os diferentes aspectos da estruturação do imaginário narrativo das crianças de 10 anos, mas vejo também muitos perigos no modo como os modelos. são compreendidos e utilizados. A partir do exame deste manual, gostaria de alarga minha proposta e, através de um rápido paralelo entre visada semiótica e visada pedagógica, tentar situar melhor os perigos de certas utilizaçōes pedagógicas das análises semióticas.
É "revelar uma axiomática" (A.J.Greimas, citado por J.Cl.Coquet no seu Semiotica Literária, 1972); é "desenvolver os níveis onde podem estar dispostas as diferenças responsáveis pela significação" (definição dada pelo grupo d'Entrevernes, no seu Análise Semiotica dos textos, 1979)

Lembremos que na exposição que fazem de suas análises de textos, os semioticistas, freqüentemente, vão da estrutura rofunda à estrutura de superfície. Courtes, por exemplo, expondo sua análise de um conto de Afanassiev (documento do "Centro de lingüística textual" da Universidade de Toulouse-Le Mirail 2, 1979) comeca pelas formas lógico-semânticas, depois passa à representação sintática, em seguida às formas discursivas, à textualizaçăo e às formas lingüísticas específicas. Da mesma forma, num estudo recente do motivo da carta no conto popular maravilhoso francês (documentos do grupo de pesquisas semio-lingüísticas do EHESS), a narrativa de referência é uma construção abstrata, à qual o autor remete tal ou ta versão do catálogo de P. Delarue e M.L.

Tenèze. A primeira etapa, a da construção dos modelos, supöe-se conhecida, o que justifica as numerosas referências a seu dicionário de semiótica (Greimas e Courtes, Hachette, 1979). Evidentemente, isso não o impediria aprovar esta resolução metodológica do grupo de Entrevernes:

Não se trata de dizer o sentido verdadeiro do texto nem de encontrar um sentido novo e inédito, fora do qual ele não teria absolutamente outro sentido... (AST, 1979,p.7)....Nāo se encontrou O sentido do texto nem se esgotou sua "mensagem", apreciar os jogos múltiplos da significação que tece este discurso...(AST,p.191, como conclusăo de uma análise da narrativa bíblica da Torre de Babel).
Assim como no caso do ponto de vis semiótico, nāo se trata de definir pedagogia em algumas linhas. Aqui, n entanto, tenho a vantagem de poder fala na primeira pessoa. A idéia que tenho da pedagogia do francês, língua e texto, é que é preciso formar leitores capazes de construir suas leituras, de dominar seus efeitos, de situá-las em relação às leituras

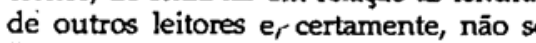
limitar a reproduzir a leitura do professor. Espero permitir que meus alunos leiam os textos de modo diferente de mim produzam sentidos diferentes daquele que produzo.

A relaçăo pedagógica está ligada ao "gesto" pedagógico. Para mim é deploráve transmitir uma análise já feita pelo professor. Vale mais a pena transmitir uma experiência. A verdadeira análise é a que comprova as hipóteses de leitura a partirdo próprio texto que as suscitou. Os exercício inspirados por um tal método são numerosos: partir da escrita de um conto recontá-lo por vários ouvintes (jogo do telefone), recolher as transformaçóes estudar suas regras; partir da leitura/escuta de um poema (näo se abandona oralidade) e passar ao ditado (transcrição como primeira etapa da análise do texto pelo auditor/copista).

Sobre o Bom Uso dos Modelos

$Q$ principal defeito dos estudantes em poética da narrativa, desde os últimos anos do curso secundário até o Magistério, é procurar nas diferentes versöes, reunidas ou recolhidas, ilustraçōes de modelos que remetam a Propp, Greimas ou Genette. A respostas propostas por esse pesquisadores elidem as questōes que deram origem às respostas. Os estudantes se esquecem de que esses modelos são construções, porque eles próprios nảo se empenharam suficientemente na construçăo de modelos. Esse empenho me parece mais importante do que o reconhecimento de modelos pré-fabricados, ou, pelo menos, uma coisa năo existe sem a outra. $O$ que precisa ser transmitido da semiótica? Seu ou seu procedimento? Sobre essa questäo do bom uso dos modelos ras ciências humanas, remeto a Oswald Ducrot que escreveu num número da revista Langue Française (12, dezembro de 1971) consagrada à "Lingüística e Matemática": Sendo a inadequação a principal força dos modelos, a indisciplina será o segredo de sua utilizaçăo.

Em pedagogia, o modelo é julgado do ponto de vista heurístico: ele ajuda a produzir leituras, a permitir que cada um situe sua leitura, ou suas leituras, em relação às dos outros leitores? Por exemplo, O Tarot dos mil e um contos, imaginado por F. Debyser (ed. l'Ècole, 1977) a partir do modelo proppiano e do romance de Italo Calvino, permite que os alunos produzam uma infinidade de narrativas ligadas entre si, como várias versōes de um mesmo tipo. Assim também a utilizaçăo do primeiro modelo actancial de Greimas na análise de versōes do "Chapeuzinho Vermelho" permite produzir leituras novas quando o lobo, a mãe, a avó ou os caçadores são substituídos para a criança enquanto sujeitos que se sucedem na busca. A cada vez organiza-se uma configuração actancial diferente e, portanto, formam-se paradigmas que remetem a cada uma das figuras e das versōes. No entanto, parece-me bastante útil passar inicialmente por uma fase de observaçăo e desconstruçấo/reconstrução de modelos, antes de fechar as leituras do texto a partir de um modelo.

Concluindo: no momento em que o conto de transmissăo oral dá a oportunidade, entre outras, de abrir o ensino da literatura para uma problemática do texto e para um verdadeiro trabalho sobre o texto (ao invés de reduzir esse ensino à transmissăo de um consenso de classe) me parece útil assinalar - perigo do desenvolvimento de um ensino pseudo-científico, que normaliza a circulação das narrativas, ao invés de estudar suas transformaçöes e favorecer sua circulaçăo. 